\title{
Morphology and aspects of growth of a trypanosome transmitted by the marine leech Johanssonia arctica (Piscicolidae) from Northern Norway
}

\author{
Egil Karlsbakk, Eli Haugen and Are Nylund
}

University of Bergen, Department of Biology, P.O. Box 7800, N-5020 Bergen, Norway

Key words: Hippoglossus, Johanssonia arctica, Trypanosoma murmanensis, Norway, marine

\begin{abstract}
The fish leech Johanssonia arctica (Johansson, 1898) was collected from king crabs Paralithodes camtschaticus (Tilesius, 1815) in Finnmark, N Norway, and allowed to feed on experimental fish hosts in the laboratory. This leech ingested blood from laboratory-reared cod (Gadus morhua) and halibut (Hippoglossus hippoglossus). Some experimental halibut acquired trypanosome infection, with parasitaemia between ca. 500 and 60,000 trypanosomes $\mathrm{ml}^{-1}$. The trypanosomes were of variable size and measured 39-90 $\mu \mathrm{m}$ (mean $57 \mu \mathrm{m}$ ) ca. 81 days post-infection. Characteristic features are cell striation, refractile cytoplasmic granules, anterior nucleus and a relatively long (ca. $6 \mu \mathrm{m}, \max 9 \mu \mathrm{m}$ ) distance from the posterior end to the kinetoplast. Following growth, the trypanosomes became increasingly slender, with fewer striae and a nucleus position less pronounced anterior. The trypanosome is considered distinct from a type transmitted by the leech Calliobdella nodulifera (Malm, 1863 ) in the NE Atlantic, but is regarded conspecific with a trypanosome transmitted by J. arctica in the NW Atlantic. This trypanosome has in the past been identified as Trypanosoma murmanensis Nikitin, 1927, a poorly described species. T. murmanensis cannot be recognized with certainty among the trypanosomes transmitted by C. nodulifera and $J$. arctica respectively. We propose that the $J$. arctica-transmitted species is considered T. murmanensis Nikitin, 1927 sensu stricto.
\end{abstract}

Johanssonia arctica (Johansson, 1898) is an Arctic leech, that in the Atlantic Ocean area occurs along the Barents Sea coasts of Russia and Norway, Eastern Greenland, and along the coast of Canada to Newfoundland (Epshtein 1968, Khan et al. 1980, Khan 1991b). It lives and reproduces at water temperatures down to $-2^{\circ} \mathrm{C}$, but survives only a few days at $5^{\circ} \mathrm{C}$ or more (Khan 1982). In the NW Atlantic, this leech species is vector of a trypanosome identified as Trypanosoma murmanensis Nikitin, 1927 (Khan 1976). Trypanosoma murmanensis was originally described from infected Atlantic cod (Gadus morhua L.) caught in the Kola fjord area, Kola Peninsula, Russian Barents Sea coast (Nikitin 1927). Niktin's description is very short and incomplete, and lacks a figure. In Western Scandinavia, trypanosomes considered similar to T. murmanensis sensu Khan $(1972,1976)$ have been recorded in resident fish species from Western Norway and Western Sweden in areas where J. arctica is not known to occur (Fänge 1979, Mork 1988), and where high water temperatures should exclude it. Another fish leech, Calliobdella nodulifera (Malm, 1863) was implied as the likely vector in these areas (Fänge 1979, Mork 1988). Recently Karlsbakk (2004) showed that $C$. nodulifera act as vector of trypanosomes infecting cod in Western Norway, and concluded that these trypanosomes differed morphologically from T. murmanensis sensu Khan (1972, 1976) transmitted by $J$. arctica in the NW Atlantic. Since both $J$. arctica and $C$. nodulifera occur along the Barents Sea coasts of the Kola Peninsula (cf. Epshtein 1968,
Utevsky and Karasev 2002), two different species of trypanosomes may occur in that area. To reveal the type of trypanosomes transmitted by $J$. arctica in the Arctic NE Atlantic, we collected leeches in the Varangerfjord area, Northern Norway, and allowed them to feed on laboratory-reared cod and halibut [Hippoglossus hippoglossus (L.)]. Infections were obtained in halibut, and the morphology and aspects of the growth of these trypanosomes is described, and compared with published descriptions of $\mathrm{N}$ Atlantic trypanosomes.

\section{MATERIALS AND METHODS}

Johanssonia arctica were collected from the carapace and legs of king crabs Paralithodes camtschaticus (Tilesius, 1815) from Varangerfjorden, Finnmark county, Northern Norway, 15-16 September 1997. These were kept in beakers on ice (water $0-2^{\circ} \mathrm{C}$ ) upon being transported to the laboratory in Bergen. There they were kept in beakers receiving running water $\left(3.5^{\circ} \mathrm{C}\right)$ until the day before use, when they were kept in standing water for further temperature decrease.

Experimental cod were reared from eggs in the laboratory, while the halibut were received as juveniles from a hatchery. These were kept in holding tanks $\left(1 \mathrm{~m}^{2}, 500 \mathrm{l}\right)$ prior to and after experimental infection with leeches in aquaria.

Individual fish were acclimated in aquaria for one week prior to being exposed to leeches at $2.3-3.5^{\circ} \mathrm{C}$. In initial trials, leeches did not feed at higher temperatures $\left(4.5-8^{\circ} \mathrm{C}\right)$. In a series of experiments, 6 halibut (17.2-24.9 cm in length) and $20 \mathrm{cod}(13.5-21.5 \mathrm{~cm})$ were exposed to one or several leeches. In one set-up, 15 January 1998, 5 halibut $(23.8-24.9 \mathrm{~cm})$ were 
exposed to 10 leeches each, with varying numbers of leeches feeding on each. After exposure, the leeches were removed from the fish and aquaria, and the water temperature gradually increased for the transfer of the fish to storage tanks $\left(1 \mathrm{~m}^{2}\right.$, $5001,7.2-8.2$, average $7.6^{\circ} \mathrm{C}$ ).

Blood samples were taken by vacutainer tubes (with EDTA), from metacaine-tranquillized fish. The fish were examined 1-2 weeks after leech infection, and if trypanosomenegative, again ca. one month post-infection (p.i.), when uninfected fish were killed. The halibut group (15 Jan) that obtained trypanosome infections was examined 16,81 and 121 days following the start of leech exposure. From the blood samples thin smears were made, and in addition bloodsmears were prepared from the most heavily infected halibut (No. 1) at 35 days. The blood was then separated by low-power centrifugation $\left(120 \mathrm{~g}, 4^{\circ} \mathrm{C}, 10 \mathrm{~min}\right)$. The buffy-coat (leucocyteplasma interface) and top leucocyte fraction was removed and aliquots examined for trypanosomes by light microscopy. Additional thin smears were prepared from the buffy-coat/ leucocyte fraction of infected fish. Air-dried blood smears were fixed in methanol and stained with Giemsa.

Trypanosome specimens encountered on a smear were measured if their body outlines were not significantly affected by adjoining blood cells, signifying that a much higher number of trypanosomes were studied than were measured. Flagellar length was not obtained for all trypanosomes, since few showed measurable flagellae. Care was taken to measure trypanosomes from both the head and tail end of smears.

Digital images of trypanosomes were obtained from a microscope (Zeiss Axioskop) via a video camera (Sony, Power HAD 3ccd colour). Measurements were taken on images with a computer program (Image Pro Plus) while still observing the trypanosome in the microscope. Trypanosome length was measured along the cell midline, from posterior end to level of kinetoplast centre (PK), kinetoplast centre to nucleus centre $(\mathrm{KN})$ and then to the start of the free flagellum (NA). Width was measured at centre of the nucleus (BWN), as well as one nuclear length anterior (BWA) and posterior (BWP) to nucleus margin. This was done to account for trypanosomes that are relatively slender, but wide at level of the nucleus, when calculating the 'slenderness' index (below). The length of a posterior unstained or pale region (PPR), nucleus dimensions ( $\mathrm{NuL}$ and $\mathrm{NuW}$ ) and area (NuA) was also measured. Phase or interference contrast was used as an aid in tracking flagellae (Flg), PK region extent and in observing striation. The following indexes were calculated: kinetoplast index $(\mathrm{KI}=$ $\mathrm{PN} / \mathrm{KN})$, nuclear index $(\mathrm{NI}=\mathrm{PN} / \mathrm{NA})$ and slenderness $(\mathrm{SL}=$ $\mathrm{BL} /$ mean $\mathrm{BW}$ ). Measurements in the text are given as range followed by the mean \pm standard deviation (SD).

All statistical analyses were performed with the program STATISTICA 6.1 (Statsoft Inc., 2003) on a PC. Pairwise comparisons were done with Student's $T$-test or with MannWhitney's $U$-test (MW) when the data were non-normally distributed. One-way analysis of variance (ANOVA) was used to compare measurements from more that two fish. Post-hoc testing was done with Newman-Keul's test. Normality testing was performed with the Normality function in the Descriptive Statistics menu of the program and heteroscedasticity was examined with Bartlett's test. Correlation between trypanosome characters (measurements, counts, indexes) was examined with the robust Spearman's rank correlation coefficients $\left(\mathrm{r}_{\mathrm{s}}\right)$.

\section{RESULTS}

Of the 19 cod exposed to Johanssonia arctica, leeches attached to 18 , fed to satiety on 15 and disappeared in 3 . None of the 18 cods became infected with trypanosomes.

A halibut fed on by one leech was also uninfected. In an experiment with 5 halibut (Nos. 1-5) being exposed to 10 leeches each, 7, 3, 9, 5 and 9 leeches attached and $6,1,5,1$ and 3 were observed to feed. Four (Nos. 1, 35) of these halibut became infected with trypanosomes. Parasitaemia was estimated at 60,000, 2,000, 500 and $30,000 \mathrm{ml}^{-1}$, respectively, at day 16 after start of leech exposure. Maximum parasitaemia was much lower ca. 81 days p.i. $(\max 17,000)$ and 121 days p.i. ( $\max 500)$. A significant proportion of the trypanosomes were removed by blood sampling, so temporal changes in the parasitaemia could not be followed.

\section{Trypanosome morphology}

Table 1, Fig. 1

The body was elongate with attenuated ends. At 16 days post-infection (d.p.i.) most flagellates appeared thickset (e.g. Fig. 1 E), but at 35 d.p.i.-on they were mostly slender (e.g. Fig. $1 \mathrm{~K}, \mathrm{~L}$ ). The posterior PK region was pointed and elongate triangular, and usually flexed away from the kinetoplastic side. Occasionally (14\%) there was a counterflexing tip (e.g. Fig. $1 \mathrm{~K}-\mathrm{N}$ ). The PK tip typically stained darker than the rest (e.g. Fig. $1 \mathrm{~L}, \mathrm{Y}$ ). The kinetoplast was located close to the flagellar side, but appeared median when the cell was thin. It was usually weakly quadrangular (Fig. $1 \mathrm{~J}$ ), trapezoid to rhomboid in outline, and measured $0.7-1.0$ $(0.9 \pm 0.1) \times 0.6-1.0(0.7 \pm 0.1) \mu \mathrm{m}(\mathrm{n}=23)$. It occasionally appeared as composed of two closely assembled rods. In some small trypanosomes the kinetoplast seemed constrained into an elongate triangular shape.

The PK region was weakly stained, and was part of a posterior pale region (PPR) that continued anterior to the kinetoplast. The transition to the stained cytoplasm tended to be distinct (e.g. Fig. 1 V), but could be gradual and PPR not measurable (Fig. 1 I, J). The PK region on average constituted $70 \%$ of this pale region.

The stained cytoplasm was granular, with darkstaining granules and small vacuoles. There were a few large vacuoles or lightly stained areas, typically 3-4 $(\max 6)$ at 16 d.p.i. and $5-6(\max 10)$ at 81 days. Of these, two were closely associated with the nucleus, one anterior and one posterior (e.g. Fig. 1 R). Both these adnuclear light areas were seen in $83 \%$, and at least one in $99 \%$ of the trypanosomes, irrespective of d.p.i. Of 490 major vacuoles or lightly stained areas registered in 103 trypanosomes, $57 \%$ were anterior to the nucleus. The trypanosomes contained prominent round refractile granules with a regular size, ca. $0.5 \mu \mathrm{m}$ in diameter. When slightly out of focus, these appeared as black grains (Fig. 1 Y, Ä). Up to 25 such granules occurred in both NA and NP regions at 16 d.p.i. (Fig. $1 \mathrm{G}, \mathrm{H}$ ), but 


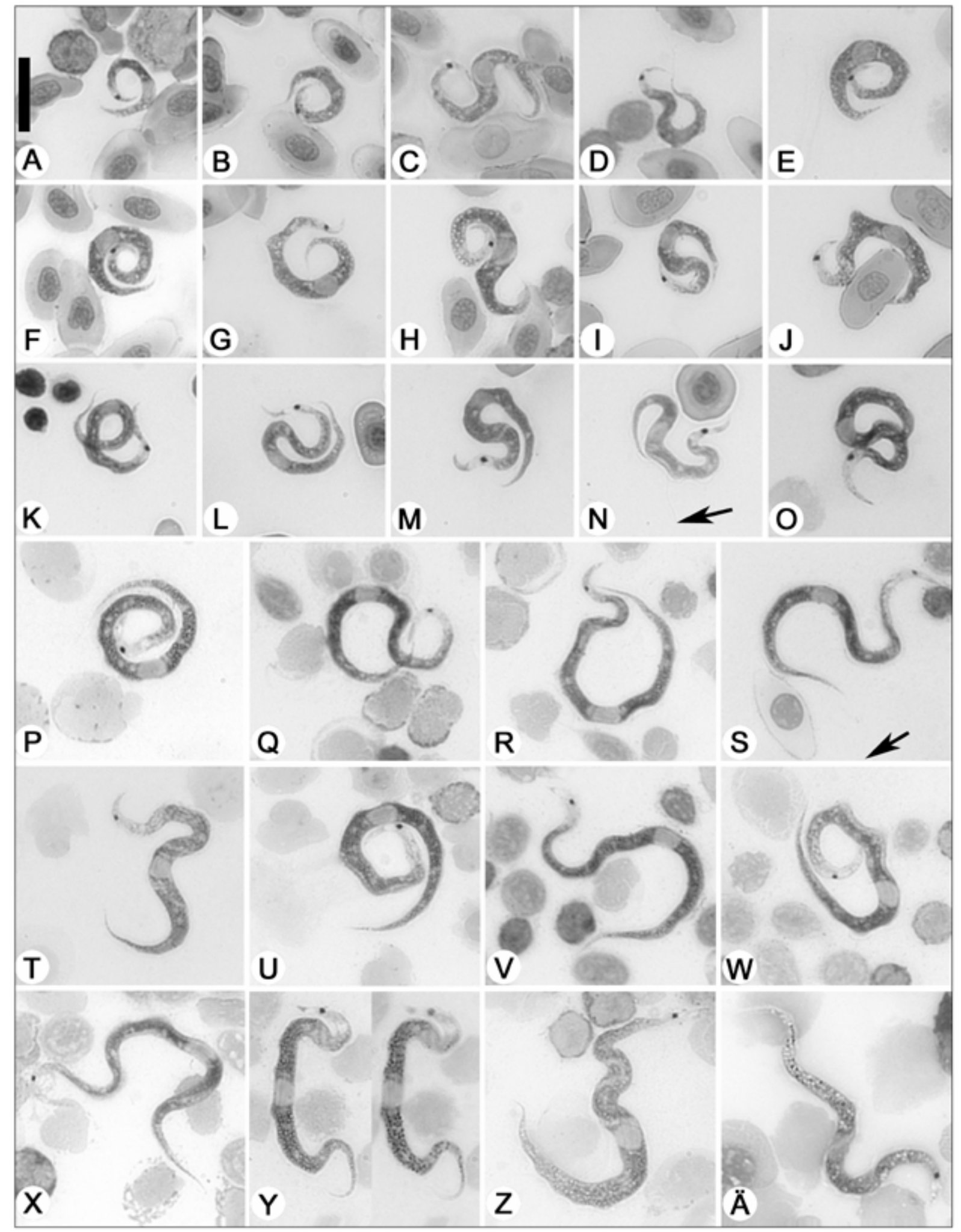

Fig. 1. Trypanosomes from halibut transmitted by the leech Johanssonia arctica, showing variation. A-J: 16 days post-infection (d.p.i.), K-O: 35 d.p.i., P-Z: 81 d.p.i., Ä: 121 d.p.i., Y: two images of same trypanosome showing appearance of refractile granules at different levels of microscope focus. Arrows indicate the end of the free flagellum. Scale bar in A for all figures $=10$ $\mu \mathrm{m}$. 
Table 1. Measurements of trypanosomes transmitted to halibut by Johanssonia arctica, on two sample dates following leech blood feeding. $\mathrm{n}=41$ day 16 and $\mathrm{n}=39$ day 81 unless otherwise stated. For the number of striae, mode is given in parenthesis. $\mathrm{SD}$ - standard deviation.

\begin{tabular}{|l|c|c|c|c|c|c|c|c|c|}
\hline \multicolumn{1}{|c|}{ Measurement } & \multirow{2}{*}{ Code } & \multicolumn{4}{c|}{ Day 16 } & \multicolumn{4}{c|}{ Day 81 } \\
& & Mean & SD & Min & Max & Mean & SD & Min & Max \\
\hline Posterior end to kinetoplast & PK & 5.0 & 0.8 & 3.4 & 7.0 & 5.8 & 1.0 & 3.7 & 8.1 \\
Kinetoplast to nucleus & KN & 16.5 & 3.4 & 4.7 & 21.8 & 24.7 & 3.9 & 18.4 & 39.0 \\
Nucleus to anterior end & NA & 15.4 & 2.4 & 10.8 & 19.8 & 26.0 & 3.7 & 15.7 & 39.2 \\
Body length & BL & 37.0 & 5.6 & 19.4 & 46.1 & 56.7 & 7.6 & 39.2 & 89.9 \\
Body width anterior & BWA & 2.2 & 0.5 & 0.7 & 3.2 & 2.0 & 0.4 & 1.4 & 2.8 \\
Body width at nucleus & BWN & 2.9 & 0.6 & 1.5 & 4.1 & 2.4 & 0.4 & 1.4 & 3.4 \\
Body width posterior & BWP & 2.4 & 0.6 & 1.2 & 3.9 & 2.0 & 0.4 & 1.4 & 2.7 \\
Nucleus length & NuL & 3.5 & 0.4 & 2.9 & 4.5 & 3.7 & 0.6 & 2.7 & 5.1 \\
Nucleus width & NuW & 2.6 & 0.6 & 1.3 & 3.6 & 2.2 & 0.4 & 1.2 & 3.0 \\
Nucleus area & NuA & 7.9 & 1.7 & 4.7 & 12.4 & 7.2 & 1.3 & 4.4 & 10.1 \\
Posterior pale region ${ }^{1}$ & PPR & 7.5 & 1.0 & 5.3 & 10.3 & 8.0 & 1.1 & 5.5 & 9.8 \\
Flagellum & Flg & 7.2 & 2.0 & 4.7 & 10.9 & 7.4 & 1.3 & 5.6 & 10.0 \\
Number of striae & NoStr & $3.7(3-4)$ & & 2 & 6 & $3.2(3)$ & & 2 & 5 \\
Kinetoplastic index $_{\text {Nuclear index }}^{\text {KI }}$ & 1.32 & 0.10 & 1.21 & 1.83 & 1.24 & 0.05 & 1.17 & 1.40 \\
Slenderness & NI & 1.41 & 0.24 & 0.80 & 2.08 & 1.19 & 0.18 & 0.91 & 1.81 \\
\end{tabular}

${ }^{1} \mathrm{n}=35$ and $27,{ }^{2} \mathrm{n}=18$ and 10 , respectively

could be $>70$ in each region at 81 or 121 d.p.i. (Fig. $1 \mathrm{P}$, $\mathrm{Y}, \mathrm{Z}, \ddot{\mathrm{A}})$. These granules may occur in rows parallel to the striae (Fig. 1 Y, Z).

Striae were always visible, generally as evenly dispersed lines parallel with the cell axis in C-shaped or spiral flagellates. Occasionally, they appeared in groups of 3 lines, flanked by apparently stria-free regions.

The nucleus was anterior, rarely equatorial or even posterior. It stained lightly with Giemsa. The nucleus was usually seen to be as wide as the cell, but in wide flagellates a fine line of cytoplasm was seen at the flagellar side. It was mostly elongate oval in shape, the exceptions being some thickset trypanosomes where the nucleus was round. A karyosome was seen at 16 d.p.i. (Fig. 1 C, E, G, I), most evident in thickset specimens and with interference contrast. At 81 d.p.i. it was generally seen as a darker round to oval region in the nucleus, 1.6-2.4 $\mu \mathrm{m}$ in diameter (Fig. $1 \mathrm{P}, \mathrm{U}$ ).

An undulating membrane was always discernible (e.g. Fig. 1 N, W), but was rarely clearly set off from the cell. It was seen as a faint oblique zone over or near the nucleus in S-shaped trypanosomes (e.g. Fig. $1 \mathrm{H}$ ); in pronounced yoke-shaped trypanosomes it traversed both anterior and posterior to the nucleus (e.g. Fig. 1 T).

\section{Growth: Between samples}

Day 16 p.i. Trypanosome length varied significantly between individual fish, those in halibut No. 1 (19.4$43.7,34.4 \pm 6.1 \mu \mathrm{m}, \mathrm{n}=21$ ) being smaller than in No. 3 and $5(33.6-46.1,39.7 \pm 3.5, \mathrm{n}=2 \times 10)$ (One-way ANOVA, $\left.F_{2,38 \mathrm{df}}=5.81, P=0.006\right)$. Unlike the infections in No. 3 and 5 , the samples from halibut No. 1 contained small trypanosomes, 19-25 $\mu \mathrm{m}$ long. Other measurements and indices did not vary significantly between these 3 halibut. Day 16 p.i. measurements are shown in Table 1.
Day 35 p.i. Trypanosomes from fish No. 1 were significantly larger than at day $16\left(T_{31 \mathrm{df}}=-7.02, P<0.001\right)$, measuring 41.9-54.1 $(47.9 \pm 3.6) \mu \mathrm{m}$ in length $(\mathrm{n}=12)$. PK distance also increased to $5.5-8.6(6.3 \pm 1.1) \mu \mathrm{m}$ $\left(T_{31 \mathrm{df}}=-3.93, P<0.001\right)$. The flagellates were more slender $(\mathrm{Sle}=22.2)$ with significantly decreased width at the nucleus (BWN), averaging $2.3 \pm 0.3 \mu \mathrm{m}$ (MW, $U$, $=196, P<0.01)$. There were corresponding decreases in nuclear dimensions (NuL, NuW, NuA). KI (1.30 \pm 0.06$)$ and NI $(1.26 \pm 0.12)$ did not change significantly from day 16 to 35 .

Day 81 p.i. The trypanosomes from halibut No. 1 had increased further in size $\left(T_{25 \mathrm{df}}=-3.65, P<0.002\right)$ (Table 1). The PK distance did not change 35-81 d.p.i. ( $T_{25 \mathrm{df}}=0.57, P=0.57$ ), but the flagellates were significantly more slender, Sle $=27.4 \pm 2.8\left(T_{25 \mathrm{df}}=-5.17\right.$, $P<0.001)$. In the same period, changes in KI or NI were not significant $\left(T_{25 \mathrm{df}}=1.86, P=0.08\right.$, and $1.76, P=$ 0.09 respectively). As on day 16, the trypanosomes in halibut No. 5 were still on average larger than those in No. 1 , measuring 46.8-89.9 $(58.8 \pm 8.2) \mu \mathrm{m}(\mathrm{n}=20)$ vs. $39.2-61.9(54.5 \pm 5.3) \mu \mathrm{m}$, but the difference was not found significant $\left(T_{33 \mathrm{df}}=-1.79, P=0.08\right)$.

Few trypanosomes were seen at 121 d.p.i., but 10 specimens from fish No. 4 were smaller (44.2-57.3, $52.6 \pm 3.8 \mu \mathrm{m})$ than those of fish No. 1 and 5 at $81 \mathrm{~d}$. They were slender $(\mathrm{Sle}=23.9)$ and with similar PK (5.7 $\mu \mathrm{m})$, KI (1.26) and NI (1.31) to the day 81 trypanosomes.

\section{Growth: Correlation between characters}

Table 2

With increasing size, the trypanosomes became increasingly slender. The length of the free flagellum appeared unaffected by size. A clear negative relationship was seen between the area of nuclei and slenderness but 
Table 2. Correlation matrix of the principal characters of Trypanosoma sp. transmitted to halibut by Johanssonia arctica. Spearman's rank correlation coefficients $\left(r_{s}\right)$ lower left, probability $(P)$ upper right. $\mathrm{n}=102$ unless otherwise stated. ns - not significant, $* P<0.05, * * P<0.01, * * * P<0.001$. Critical values determining significance were determined with sequential Bonferroni corrections $(k=55)$.

\begin{tabular}{|l|c|c|c|c|c|c|c|c|c|c|c|c|}
\hline \multicolumn{1}{|c|}{ Measurement } & Code & BL & PK & PPR & BWN & NuL & NuA & Flg & NoStr & KI & NI & Sle \\
\hline Body length & $\mathrm{BL}$ & & $* * *$ & $* * *$ & $\mathrm{~ns}$ & $*$ & $\mathrm{~ns}$ & $\mathrm{~ns}$ & $\mathrm{~ns}$ & $* * *$ & $* *$ & $* * *$ \\
Posterior end to kinetoplast & $\mathrm{PK}$ & 0.59 & & $* * *$ & $\mathrm{~ns}$ & $\mathrm{~ns}$ & $\mathrm{~ns}$ & $\mathrm{~ns}$ & $\mathrm{~ns}$ & $\mathrm{~ns}$ & $\mathrm{~ns}$ & $* * *$ \\
Posterior pale region & $\mathrm{PPR}^{1}$ & 0.50 & 0.72 & & $\mathrm{~ns}$ & $\mathrm{~ns}$ & $\mathrm{~ns}$ & $\mathrm{~ns}$ & $\mathrm{~ns}$ & $\mathrm{~ns}$ & $\mathrm{~ns}$ & $\mathrm{~ns}$ \\
Body width at nucleus & $\mathrm{BWN}$ & -0.17 & -0.13 & 0.07 & & $\mathrm{~ns}$ & $* * *$ & $\mathrm{~ns}$ & $* * *$ & $\mathrm{~ns}$ & $\mathrm{~ns}$ & $* * *$ \\
Nucleus length & $\mathrm{NuL}$ & 0.33 & 0.05 & 0.20 & 0.24 & & $* * *$ & $\mathrm{~ns}$ & $\mathrm{~ns}$ & $\mathrm{~ns}$ & $\mathrm{~ns}$ & $\mathrm{~ns}$ \\
Nucleus area & $\mathrm{NuA}$ & -0.01 & -0.09 & 0.15 & 0.77 & 0.65 & & $\mathrm{~ns}$ & $* * *$ & $\mathrm{~ns}$ & $\mathrm{~ns}$ & $* *$ \\
Free flagellum & $\mathrm{Flg}$ & 0.20 & 0.13 & 0.14 & -0.19 & -0.22 & -0.23 & & $\mathrm{~ns}$ & $\mathrm{~ns}$ & $\mathrm{~ns}$ & $\mathrm{~ns}$ \\
Number of striae & NoStr & -0.09 & -0.02 & 0.01 & 0.75 & 0.17 & 0.59 & -0.22 & & $\mathrm{~ns}$ & $\mathrm{~ns}$ & $* * *$ \\
Kinetoplastic index & $\mathrm{KI}$ & -0.50 & 0.28 & 0.14 & 0.02 & -0.27 & -0.12 & 0.00 & 0.01 & & $\mathrm{~ns}$ & $* * *$ \\
Nuclear index & $\mathrm{NI}$ & -0.38 & -0.15 & -0.05 & 0.14 & -0.17 & 0.02 & -0.30 & 0.10 & -0.06 & & $\mathrm{~ns}$ \\
Slenderness & $\mathrm{Sle}$ & 0.84 & 0.49 & 0.34 & -0.58 & 0.14 & -0.38 & 0.24 & -0.47 & -0.44 & -0.29 & \\
\hline
\end{tabular}

$$
{ }^{1} \mathrm{n}=79,{ }^{2} \mathrm{n}=40,{ }^{1,2} \mathrm{n}=38
$$

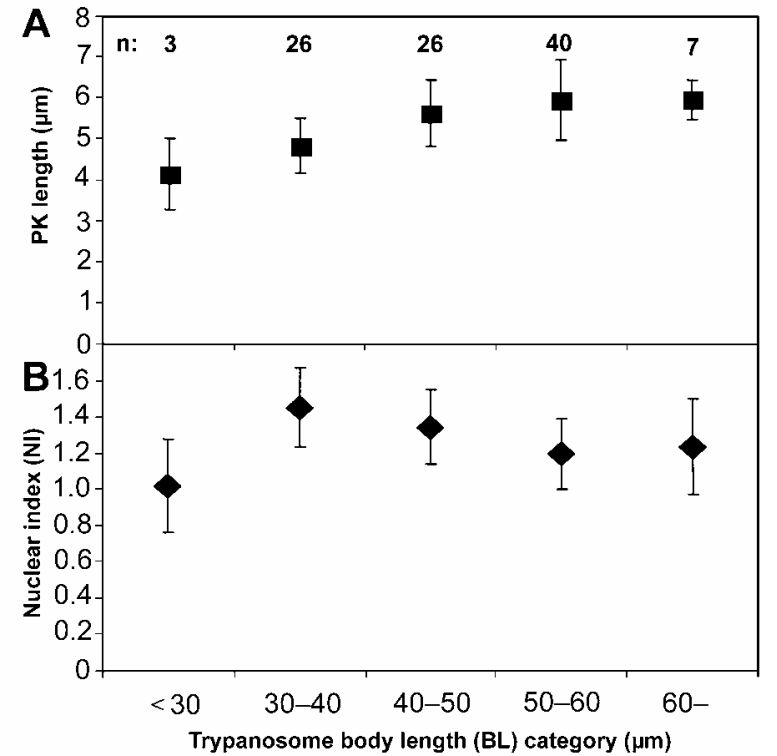

Fig. 2. Trypanosomes from halibut transmitted by the leech Johanssonia arctica. Changes in length of posterior end to kinetoplast (PK) (A) and in nuclear position measured with the nuclear index (NI) (B), in $10 \mu \mathrm{m}$ trypanosome body length (BL) categories. The first and last categories contains flagellates $<30 \mu \mathrm{m}$ and $>60 \mu \mathrm{m}$ in $\mathrm{BL}$ respectively. Bars represent standard deviations, numbers on top in (A) give sample size (n: numbers measured).

not with body length. PK length and posterior transparent region (PPR) extent increased with trypanosome length. The changes in average PK length with trypanosome size is visualised in Fig. $2 \mathrm{~A}$, showing a possible tendency that PK length-increase levels off at body lengths exceeding 50-60 $\mu \mathrm{m}$. Kinetoplast dimensions did not correlate with body length $\left(r_{s}=-0.22, P=0.32\right.$, $\mathrm{n}=23$ ). Number of striae at level of the nucleus was affected by width and width-related measures, i.e. increased with BWN, NuA and decreasing slenderness.
Both KI and NI tended to decrease with body length, and KI also with increasing slenderness. The changes in average NI with trypanosome size is visualised in Fig. 2 B. Notably, some very small trypanosomes (19-25 $\mu \mathrm{m})$ had a more central nucleus.

\section{DISCUSSION}

In the NW Atlantic, the most common source of blood meals to Johanssonia arctica is flatfish (Khan 1991a, b), with cod being rare. Results from Newfoundland also suggest that trypanosome infection in the leech is acquired mainly from flatfish (Khan 1991a). Atlantic halibut have rarely been examined for trypanosomes, but 1 of 7 examined from the Newfoundland-Labrador area and 2 of 5 from the Davis Strait region were found infected (Khan et al. 1980, 1991). The likely vector in both areas was considered to be J. arctica. Hence there are good arguments for the use of flatfish such as halibut as an experimental host. Khan $(1976,1977)$ readily infected cod with $J$. arctica that transmitted trypanosomes. Since in the present study all cod and 2 of 6 halibuts fed on by $J$. arctica remained uninfected, these leeches likely did not harbour trypanosomes. Some trypanosome infections in the leeches may have been lost due to leech starvation (cf. Khan 1978).

Comparison with marine trypanosomes from Western Europe is difficult due to mostly brief and inaccurate descriptions. Of NE Atlantic trypanosomes, the size and proportions of the present trypanosome ("JA"-type) is closest to T. callionymi Brumpt et Lebailly, 1904, Trypanosoma sp. of Fänge (1979), Trypanosoma sp. of Robertson (1906), Trypanosoma murmanensis Nikitin, 1927 and Trypanosoma sp. of Karlsbakk (2004). T. callionymi measures $65 \mu \mathrm{m}$ in length, of which the PK region is stated to constitute $11 \mu \mathrm{m}$ (Brumpt and Lebailly 1904, Lebailly 1906). If those measurements are representative, then $T$. callionymi is distinguished from the present form by PK extent. The trypanosome found 
by Robertson (1906) in Scottish flatfish is very similar to a type transmitted by the leech Calliobdella nodulifera to cod (cf. Karlsbakk 2004) (henceforth "CN"-type), except that it is figured with a distinct karyosome. It appears to be distinguished from the present trypanosome by a short PK region and less granular cytoplasm. The form briefly described by Fänge (1979) from Enchelyopus cimbrius (L.) in Sweden is also very similar to the CN-trypanosome, by size, NI and cytoplasm structure, but was reported to have a PK length averaging $6.3 \mu \mathrm{m}$ and reaching $10 \mu \mathrm{m}$, which is more in agreement with the present observations.

The morphology of the trypanosomes from the experimentally infected halibut (JA-type) differs from those described by Karlsbakk (2004), transmitted to cod by the leech Calliobdella nodulifera (CN-type), in at least five features:

1. The JA-type reaches a larger size, $\max 90 \mu \mathrm{m}$ at 81 d.p.i. vs. max. $66 \mu \mathrm{m}$ within 113 d.p.i. for the $\mathrm{CN}$ type.

2. The JA-type shows a long PK region that grows with body length, while the PK length of the CN-trypanosome was short and unaffected by length-growth.

3. The JA-flagellates tend to have a relatively darkstained region posterior in $\mathrm{PK}$.

4. The CN-trypanosome has a nearly central nucleus, while it is anterior in the JA-type.

5. The cytoplasm in the JA-type appears markedly more vacuolate and contains refractive granules.

In addition, the JA-trypanosome shows size-pleomorphism, while the CN-type varied little in length in the study by Karlsbakk (2004), and a karyosome, seen in larger JA-flagellates, is rarely evident in the $\mathrm{CN}$ trypanosome.

By all these characters the present trypanosome conforms to the species described from the Canadian Atlantic (So 1972, Khan 1972, 1976, 1977), shown by Khan $(1976,1977)$ to be transmitted by J. arctica. Although Khan did not mention the dark PK tip, or refer to the refractile granules explicitly, his (1976) figures show these features (e.g. figs. 31-34 and figs. 30-31 respectively). Hence it appears that this leech species transmits the same trypanosome to teleost fish in these regions, likely throughout its Atlantic range.

Several infected leeches may have initiated the infections studied here. Despite this, there is a remarkable variation in trypanosome size several months after infection, e.g. 39-90 $\mu \mathrm{m}$ after 81 days. The same observation was made by Khan (1976), who concluded that the trypanosome is pleomorphic. There is no evidence that this trypanosome divides in the fish host (Khan 1976, present observations), but it is possible that division occurs among the initial stages in the kidney, as observed by Fantham et al. (1942) for Trypanosoma myoxocephali Fantham, Porter et Richardson, 1942. However, the size variation may also arise from differing growth or variation in the infective stages from the leech. Khan (1976) observed both epimastigotes and metatrypanosomes in the proboscis region of $J$. arctica and these may be of varying size.

The growth of the $J$. arctica-transmitted trypanosome was slower in the present experiments than in those of Khan (1976), our trypanosomes averaging $57 \mu \mathrm{m} 81$ d.p.i. while Khan's averaged $58 \mu \mathrm{m}$ at 23 d.p.i. Also, Khan (1976) described and figured the trypanosomes at this stage as more thickset and with a higher number of striae, 6-10 (as "myonemes"). An important difference in these experiments is the temperature at which the fish were kept, in our case $7.2-8.2^{\circ} \mathrm{C}$ and by Khan at -1 to $3^{\circ} \mathrm{C}$. Since the leech host of this trypanosome is restricted to cold waters $\left(<4^{\circ} \mathrm{C}\right)$, it is plausible that the optimal growth of the trypanosome parasite is at low temperatures. Host-induced differences in growth, i.e. cod vs. halibut, are unlikely according to the studies of Khan (1977), who infected cod and three species of pleuronectids with trypanosomes from $J$. arctica. During the two months studied, his trypanosomes did not show differences in morphology and morphometry between hosts.

The growth patterns observed here largely agree with the observations of Khan (1976), who found that the position of the nucleus and kinetoplast and length of the free flagellum did not change significantly with growth, while PK, NA, KN and total length grew at the same rate, ca. $5 \%$ day $^{-1}$. Contrary to Khan (1976), we detected significant changes in KI and NI with increased length, but these represented decreases in the approximate same range (1.5-1.3 and 1.4-1.3 respectively) as he reported for trypanosomes $>25 \mu \mathrm{m}$.

The realisation that the two fish leeches Johanssonia arctica and Calliobdella nodulifera may transmit different trypanosome species, complicates the identity of Trypanosoma murmanensis Nikitin, 1927. Nikitin (1927) bought locally caught cod from fishermen in Aleksandrovsk (Polyarny) and Mogil'noe (Kil'din Island) (both in the Kola Fjord area), and found 4 of 15 cod infected with trypanosomes. Both leech species occur in the area (Epshtein 1968, Utevsky and Karasev 2002). In Nikitin's brief description, he records the following characteristics: "body 57-60 $\mu \mathrm{m}$, with numerous clear vacuoles, flagellum short, posterior end rounded, pale violet nucleus in the middle of body, blepharoblast (=kinetoplast) only seen in one case as a point". Since Nikitin observed four infections and it appears from his description that he had observed many trypanosomes (e.g. "...found most trypanosomes in the blood, very few in smears and squash preparations of the spleen..."), the narrow size range is most in agreement with the $\mathrm{CN}$ type. Though the accuracy of Nikitin's statements cannot be known, a "nucleus in the middle of the body" and a "rounded posterior end" also suggest that type. However, the notion that the cytoplasm is very vacuolate is most suggestive of the JA-trypanosome. The types of Nikitin's trypanosome cannot be located (stated to be 
stored at the Zoological Laboratory, Odessa Institute of Peoples Education [Inst. Nar. Obr.]). Consequently, $T$. murmanensis Nikitin, 1927 cannot be identified with certainty. The binomen have for more than 30 years been applied to the well-known trypanosome species transmitted by J. arctica (e.g. Khan 1972, 1976, 1977). The principle of stability in nomenclature leads us to propose that this species is considered T. murmanensis Nikitin, 1927 sensu stricto.

Acknowledgements. Frank Midtøy is thanked for help in rearing the fish. The study was funded by Norwegian Research Council grant no. 109283/410.

\section{REFERENCES}

BRUMPT E., LEBAILLY C. 1904: Description de quelques nouvelles espèces de trypanosomes et d'hémogrégarines parasites des téléosteens marins. C. R. Acad. Sci. Paris 139: 613-615.

EPSHTEIN V.M. 1968: [Revision of the genera Oxytonostoma and Johanssonia (Hirudinea, Piscicolidae)]. Zool. Zh. 42: 1011-1021. (In Russian.)

FANTHAM H.B., PORTER A., RICHARDSON L.R. 1942 Some haematozoa observed in vertebrates in eastern Canada. Parasitology 34: 199-226.

FÄNGE R. 1979: Protozoan infections (haemogregarines, trypanosomes) of the blood of the gadoid fish, Melanogrammus aeglefinus (haddock) and Gaidropsaurus cimbrius (four-bearded rockling). Acta Zool. (Stockh.) 60: 129-137.

KARLSBAKK E. 2004: A trypanosome of Atlantic cod, $G a-$ dus morhua L., transmitted by the marine leech Calliobdella nodulifera (Malm, 1863) (Piscicolidae). Parasitol. Res. 93: 155-158.

KHAN R.A. 1972: On a trypanosome from the Atlantic cod, Gadus morhua L. Can. J. Zool. 50: 1051-1054.

KHAN R.A. 1976: The life cycle of Trypanosoma murmanensis Nikitin. Can. J. Zool. 54: 1840-1849.

KHAN R.A. 1977: Susceptibility of marine fish to trypanosomes. Can. J. Zool. 55: 1235-1241.

KHAN R.A. 1978: Longevity of Trypanosoma murmanensis in the marine leech, Johanssonia sp. Can. J. Zool. 56: 2061-2063.

KHAN R.A. 1982: Biology of the marine piscicolid leech Johanssonia arctica (Johansson) from Newfoundland. Proc. Helminthol. Soc. Wash. 49: 266-278.
KHAN R.A. 1991a: Prevalence of trypanosome infections in the marine leech Johanssonia arctica off eastern Newfoundland. Can. J. Zool. 69: 1194-1198.

KHAN R.A. 1991b: Trypanosome occurrence and prevalence in the marine leech Johanssonia arctica and its host preferences in the northwestern Atlantic Ocean. Can. J. Zool. 69: 2374-2380.

KHAN R.A., BARRETT M., MURPHY J. 1980: Blood parasites of fish from the northwestern Atlantic Ocean. Can. J. Zool. 58: 770-781.

KHAN R.A., LEE E.M., WHITTY W.S. 1991: Blood protozoans of fish from the Davis Strait in the northeastern Atlantic Ocean. Can. J. Zool. 69: 410-413.

LEBAILLY C. 1906: Recherches sur les hèmatozaires parasites des téléosteens marins. Arch. Parasitol. 10: 348-404.

MORK J. 1988: Prevalence of the haemoflagellate Trypanosoma sp. in some common Norwegian marine fish species. Sarsia 73: 263-266.

NIKITIN S. 1927: [On the blood parasites in northern vertebrates]. Russ. Zh. Trop. Med. 5: 350-356. (In Russian.)

ROBERTSON M. 1906: Notes on certain blood-inhabiting Protozoa. Proc. R. Phys. Soc. Edinb. 16: 232-247.

SO B.K.F. 1972: Marine fish haematozoa from Newfoundland waters. Can. J. Zool. 50: 543-554.

UTEVSKY S.Yu., KARASEV A.V. 2002: First record of the piscicolid leech Calliobdella nodulifera (Hirudinea, Piscicolidae) from the Russian Northern Seas. Vestn. Zool. 36(4): 34 . 